\title{
Inspeção de Obra de Arte Especial utilizando a metodologia GDE/UnB
}

\author{
D.F. RIBEIRO ${ }^{1}$; M. A. MACHADO ${ }^{2} ;$ A. R. A. OMORE'; P. V.G. FREITAS \\ V. A. COELHO $;$; F. G. S. SILVA ${ }^{6}$; \\ *Autor de Contato: marina.machado@outlook.com \\ ${ }^{1}$ Engenheiro Civil, UNIJORGE, Salvador, Brasil \\ ${ }^{2}$ Graduada em Engenharia Civil, Escola Politécnica, Universidade Federal da Bahia, Salvador, Brasil \\ ${ }^{3}$ Graduado em Engenharia Civil, Escola Politécnica da UFBA, Salvador, Brasil \\ ${ }^{4}$ Área de construção civil, SENAI CIMATEC, Salvador, Brasil \\ ${ }_{5}^{5}$ PPEC, Escola Politécnica, Universidade Federal da Bahia, Salvador, Brasil \\ ${ }^{6}$ Departamento de Construção e Estruturas, Universidade Federal da Bahia, Salvador, Brasil
}

\begin{abstract}
RESUMO
O presente trabalho teve como objetivo inspecionar o viaduto Marta Vasconcelos, na cidade de Salvador, com a aplicação da metodologia GDE/UnB, quantificando seu nível de degradação, classificado como crítico, com a necessidade de inspeção especial de acordo a NBR 9452 (2016) e prazo de intervenção imediata. A metodologia se mostrou apropriada ao estudo desta estrutura, estando o resultado coerente com o observado em vistoria, onde se constatou a presença de diversas manifestações patológicas, das quais se destacam: ausência de recobrimento, oxidação das armaduras, desplacamento de concreto e ausência de tratamento nas juntas de dilatação. A cidade apresenta diversas obras de arte especiais em situação semelhante à analisada e entende-se necessário que sejam realizadas inspeções e intervenções emergenciais pelo poder público.
\end{abstract}

Palavras-chave: Viadutos; Degradação; Inspeção. 


\title{
Inspection of bridges using the GDE/UnB methodology
}

\begin{abstract}
This study aimed to inspect Marta Vasconcelos viaduct, in the city of Salvador, with the application of the GDE/UnB methodology, quantifying its degradation level, classified as critical, with the need for special inspection according to NBR 9452 (2016), with immediate intervention deadline. The GDE/UnB methodology proved to be appropriate for this study, and the result was consistent with the expectation generated after its inspection, which revealed several pathological manifestations such as: lack of coating, oxidation of reinforcement, concrete peeling and no treatment in expansion joints. Salvador has several bridges and viaducts in a similar situation to the one analyzed, it is necessary to carry out inspections and adoption of emergency interventions by the government.
\end{abstract}

Keywords: Viaducts; Degradation; Inspection.

\section{Inspección de puentes utilizando la metodología GDE/UnB}

\section{RESUMEN}

El presente trabajo tuvo como objetivo inspeccionar el viaducto Marta Vasconcelos, en Salvador, con aplicación de la metodología GDE/UnB, cuantificando su nivel de degradación, clasificado como crítico, con necesidad de inspección especial, según NBR 9452 (2016), con un período de intervención inmediata. La metodología GDE/UnB se mostró apropiada para el estudio de esta estructura, encontrándose el resultado consistente con la expectativa generada luego de su inspección, donde se encontraron varias manifestaciones patológicas, entre las que destacan las siguientes: Ausencia de recubrimiento, oxidación del refuerzo, pelado del hormigón y sin tratamiento en juntas de dilatación. La ciudad tiene varios viaductos en situación similar a la analizada, se considera necesario realizar intervenciones de emergencia por parte del gobierno.

Palabras clave: Viaductos; Degradación; Inspección.

\section{INTRODUÇÃO}

O advento do concreto armado possibilitou a construção de estruturas capazes de vencer grandes vãos, em alturas elevadas, diferentemente do que se observa em construções históricas, estas, executadas, de forma geral, como estruturas em arco, trabalhando quase que exclusivamente sob compressão, com mínimos esforços de tração. Tão logo se verificou a eficiência do concreto armado para estruturas com estas características, este passou a ser utilizado em larga escala na construção de pontes e viadutos, que são estruturas destinadas à transposição de obstáculo à continuidade do leito normal de uma via. 
Conforme Costa (2016), obras de arte especiais (OAE) caracterizam-se por construções diferenciadas, o que se deve à sua funcionalidade e aos esforços aos quais se submetem normalmente.

As OAE estão, de forma geral, constantemente, submetidas a condições climáticas intensas e variadas, e utilização constante, necessitando, desta forma, de um planejamento de inspeções periódicas, para aferição e acompanhamento do seu nível de degradação, assim como definição de medidas corretivas e seus prazos de execução. A NBR 9452 (ABNT, 2016) preconiza, dentre outros aspectos, os tipos de inspeção para as OAE, sendo estas, conforme normatizado:

- Inspeção Inicial ou Cadastral, que se trata primeira inspeção da obra e deve ser efetuada imediatamente após concluída esta, outras etapas posteriores, ou quando houver alterações;

- Inspeção Rotineira, acompanhamento periódico, visual, sem utilização de equipamentos e/ou recursos especiais para análise ou acesso, realizada em prazo não superior a um ano;

- Inspeção Especial, deve incluir mapeamento gráfico e quantitativo das manifestações patológicas dos elementos aparentes e/ou acessíveis da obra de arte especial, objetivando diagnósticos;

- Inspeção Extraordinária, ocorre por eventos não programados como: impacto causados por acidentes; fenômenos naturais e outros.

De acordo com Bertolini (2010), a partir da década de 1980, se fez necessário, a inspeção mais criteriosa das manifestações patológicas em estruturas de concreto, devido à grande quantidade de eventos de degradação acelerada, gerando riscos à segurança e elevados custos de manutenção.

Vale ressaltar que custos de manutenção e inspeção, tendem ser consideravelmente inferiores aos custos de recuperação de estruturas, e, tais medidas devem ser adotadas, não só pela economia financeira, como também pela segurança e manutenção da utilidade e finalidade da estrutura. Segundo Hyall (2010), a degradação de uma estrutura é afetada, dentre outros motivos, pela sua forma, materiais empregados e qualidade da construção, ação do fogo, natureza e intensidade do tráfego.

De acordo com o Manual de Uso, Operação e Manutenção NBR 15575-1 (ABNT, 2013), uma determinada estrutura apresenta uma vida útil estimada, durante a qual o projeto deverá atender de forma eficiente sua finalidade, conforme sua devida utilização e planos de manutenção. A vida útil estimada para OAE é de 25 anos, conforme estudo de caso realizado por Verderesi (2015).

O conceito de durabilidade e desempenho das OAEs, conforme a NBR 6118 (ABNT, 2014), consiste na sua capacidade, em manter-se segura e estável durante o período de sua vida útil estando submetida a determinada classe de agressividade ambiental.

Destacam-se alguns danos mais frequentes em estrutura de concreto, estes verificados na OAE inspecionada, conforme Manual de Aplicação da Metodologia GDE/UnB a OAEs, sendo estes: carbonatação; cobrimento deficiente; contaminação por cloretos; corrosão de armaduras; desagregação do concreto; eflorescência; fissuração; manchas; obstrução de juntas de dilatação; sinais de esmagamento do concreto; umidade excessiva.

Quanto a definição de patologias, Helene (1997) afirma tratar-se de ramo da engenharia que estuda os sintomas, os mecanismos, as causas e as origens dos defeitos das construções civis, enquanto Cánovas (1988), descreve a patologia com sendo campo de estudos que analisa os mecanismos, sintomas, causas e origens dos defeitos construtivos, sendo possível, em situações específicas, realizar um diagnóstico através de verificação sensorial, como a metodologia GDE/UnB, adotada neste trabalho. 
Segundo Costa (2016), a metodologia GDE/UnB, adaptada por Verly (2015), atende à finalidade de inspecionar danos em Obras de Arte Especiais, devendo, este, porém, passar por melhorias ao longo do tempo conforme se aprofundam os estudos e práticas de sua aplicação. Verifica-se em Verly (2015) que a metodologia GDE/UnB necessitava de adaptações para sua aplicação em OAEs, tendo sido ajustada para esta finalidade, conforme demonstrado em seu trabalho.

O objetivo deste trabalho é apresentar estudo de caso de inspeção visual de uma OAE, parametrizando e mensurando as manifestações patológicas encontradas, apresentando quantitativamente o nível de deterioração e prazo para intervenção.

\section{MÉTODOLOGIA GDE/UnB}

No estudo de caso apresentado adotou-se a metodologia GDE/UnB adaptada e aperfeiçoada para inspeção em OAEs por Verly (2015). A metodologia foi desenvolvida, primordialmente, por Castro (1994), e aperfeiçoada por Euqueres (2011).

A metodologia utilizada consiste na inspeção visual que possibilite a mensuração, quantificação e definição do grau de deterioração de determinada estrutura. Esta permite uma classificação com menor subjetividade inerente ao profissional, em relação ao estado da estrutura, através de padronização e quantificação das circunstâncias observadas.

Ainda de acordo com Verly (2015), o perito, após efetuar inspeção visual deve proceder com as seguintes etapas para aplicação do método:

i. Classificação dos elementos distintos em famílias, de acordo com suas funções e importância na estrutura.

ii. Relacionar cada dano, de cada elemento, ao seu respectivo fator de ponderação - Fp, de acordo com os valores recomendados:

Tabela 1 - Famílias de elementos estruturais e fatores de ponderação (Fp) - Manual de Aplicação da Metodologia GDE/UnB

\begin{tabular}{|c|l|c|}
\hline Danos & \multicolumn{1}{|c|}{ Patologias } & Fp \\
\hline 1 & Carbonatação & 3 \\
\hline 2 & Cobrimento Deficiente & 3 \\
\hline 3 & Contaminação por Cloretos & 4 \\
\hline 4 & Corrosão de Armaduras & 5 \\
\hline 5 & Desagregação & 3 \\
\hline 6 & Desvio de Geometria & 4 \\
\hline 7 & Eflorescência & 2 \\
\hline 8 & Desplacamento & 3 \\
\hline 9 & Fissuras & 2 a $5^{*}$ \\
\hline 10 & Umidade Excessiva na Estrutura & 4 \\
\hline 11 & Manchas & 3 \\
\hline 12 & Recalque & 5 \\
\hline 13 & Sinais de Esmagamento & 5 \\
\hline 14 & Umidade na Base & 3 \\
\hline
\end{tabular}


Os valores Fp devem ser preenchidos previamente à inspeção, exceto o item fissuras, cujo valor de Fp é definido no momento da inspeção de acordo com as Tabelas de Classificação de fissuras em elementos de concreto armado e fatores de ponderação indicados (Fp) do Manual de Aplicação da Metodologia GDE/UnB.

i. Relacionar cada dano ao fator de intensidade - Fi respectivo nas famílias, conforme pode se verificar no Manual de Aplicação da Metodologia GDE/UnB, na Tabela de Classificação dos danos e fatores de intensidade (Fi).

ii. Calcular Grau do Dano - D, de acordo com as seguintes equações (1) e (2):

$D=0,8 \times F i \times F p$ para $F i \leq 2,0$

$D=(12 \times F i-28) \times F p \quad$ para $F i \geq 3,0$

iii. Calcular o Grau de Deterioração do elemento - Gde, realizando análise do conjunto de elementos, conforme a seguinte equação (3):

$G d e=D m a ́ x \times\left[\frac{1+\left(\sum_{i=1}^{n} D i\right)-D m a ́ x}{\sum_{i=1}^{n} D i}\right]$

Onde:

Gde $=$ Grau de deterioração do elemento;

$\mathrm{Di}=$ Grau do dano de índice "i";

Dmáx = Maior grau de dano encontrado no elemento;

$\mathrm{n}=$ Número de danos encontrados no elemento.

iv. Calcular o Grau de Deterioração da família - Gdf, cujo objetivo é analisar o conjunto dos elementos da mesma família, conforme a seguinte equação (4):

Gdf $=$ Gde, máx $\sqrt{1+\frac{\left(\sum_{i=1}^{n} G d e, i\right)-G d e, \text { máx }}{\sum_{i=1}^{m} G d e, i}}$

Onde:

Gde,máx = Maior grau de deterioração encontrado na família do elemento;

Gde, $\mathrm{i}=$ Graus de deterioração apresentados pelos elementos da família $(\geq 15)$;

$\mathrm{m}=$ número de Elementos com Gde $\geq 15$.

Deve ser observado que na Equação 4 são considerados apenas os valores de Gde iguais ou superiores a 15. A necessidade de consideração de um valor mínimo para o Gde foi constatada no desenvolvimento da metodologia por Castro (1994), que simulou a ocorrência simultânea de todos os danos possíveis em uma determinada família, onde foi atribuído o valor de Fi igual a 2,5 para todos os danos. O processo foi repetido para todas as famílias, obtendo-se para todas elas valores de Gde próximos a 15, surgindo então a recomendação de utilização apenas de valores iguais ou superiores a 15. 
v. Introduzir o Fator de Relevância Estrutural - Fr relativa a cada família de elementos em relação a toda a estrutura, conforme divisão adotada por Euqueres (2011) e Verly (2015), conforme segue:

Tabela 3 - Fatores de relevância estrutural para OAEs (adaptado de Verly, 2015)

\begin{tabular}{|l|c|}
\hline \multicolumn{1}{|c|}{ Família } & Fr \\
\hline Barreiras, quarda-corpo, guarda-rodas, pista de rolamento & 1 \\
\hline Juntas de dilatação & 2 \\
\hline Transversinas, cortinas, alas & 3 \\
\hline Lajes, fundações, vigas secundárias, aparelhos de apoio & 4 \\
\hline Vigas e pilares principais & 5 \\
\hline
\end{tabular}

vi. Calcular o Grau de Deterioração da Estrutura - Gd, a partir dos valores de Gdf calculados ponderados pelo fator de relevância estrutural (Fr) para cada família, conforme a seguinte equação (5):

$G d=\frac{\sum_{i=1}^{k}(F r, i \times G d f, i)}{\sum_{i=1}^{k} F r, i}$

Onde:

$\mathrm{k}=$ Número de famílias da estrutura;

Fr,i = Fator de relevância estrutural da família de ordem “i”;

Gdf,i = Grau de deterioração da família de ordem "i”".

vii. Por fim, conforme o valor de Gd calculado, define-se a ação a ser recomendada, de acordo com a Metodologia GDE/UnB, conforme segue:

Tabela 4 - Classificação dos níveis de deterioração da estrutura e ações recomendadas em função dos valores de Gd (adaptado de Verly, 2015)

\begin{tabular}{|l|c|l|}
\hline $\begin{array}{c}\text { Nível de } \\
\text { Deterioração }\end{array}$ & Gd & \multicolumn{1}{c|}{ Ações a serem adotadas } \\
\hline Baixo & $0-15$ & Estado aceitável. Manutenção preventiva. \\
\hline Médio & $15-50$ & $\begin{array}{l}\text { Definir prazo/natureza para nova inspeção. Planejar intervenção } \\
\text { em longo prazo (máximo 2 anos). }\end{array}$ \\
\hline Alto & $50-80$ & $\begin{array}{l}\text { Definir prazo/natureza para inspeção especializada detalhada. } \\
\text { Planejar intervenção em médio prazo (máximo 1 ano). }\end{array}$ \\
\hline Sofrível & $80-100$ & $\begin{array}{l}\text { Definir prazo/natureza para inspeção especializada detalhada. } \\
\text { Planejar intervenção em curto prazo (máximo 6 meses). }\end{array}$ \\
\hline Crítico & $>100$ & Inspeção especial emergencial. Planejar intervenção imediata. \\
\hline
\end{tabular}




\section{OBJETO DE ESTUDO}

Esta OAE se trata, de fato, de um complexo composto por duas estruturas semelhantes, porém, independentes, cada uma destas atendendo a um sentido de tráfego. O presente trabalho consistiu na inspeção do Viaduto II, situado ao lado direito no sentido Norte - Sul, cujo tráfego consiste no sentido Comércio - BR 324.

O Viaduto Marta Vasconcelos II está localizado no bairro do Aquidabã, na cidade de Salvador (Figuras 1 e 2) e apresenta comprimento de cerca de 129,00 metros, largura total de 9,50 metros, duas faixas de rolamento. Este apresenta 8 pilares, dispostos em 4 pares, formando assim 5 vãos. Os pilares foram numerados no sentido Norte - Sul, da esquerda para a direita, sendo pilar esquerda da primeira linha de pilares considerado como $n^{0} 1$, aquele à sua direita $n^{0} 2$, e assim sucessivamente. Os vãos foram numerados no sentido Norte - Sul, sendo o vão $\mathrm{n}^{0} 1$, aquele situado entre a cabeceira e os pilares 1 e 2 , o vão $n^{\circ} 2$ situado entre os pilares 1 e 2 , e os pilares 3 e 4, assim sucessivamente.

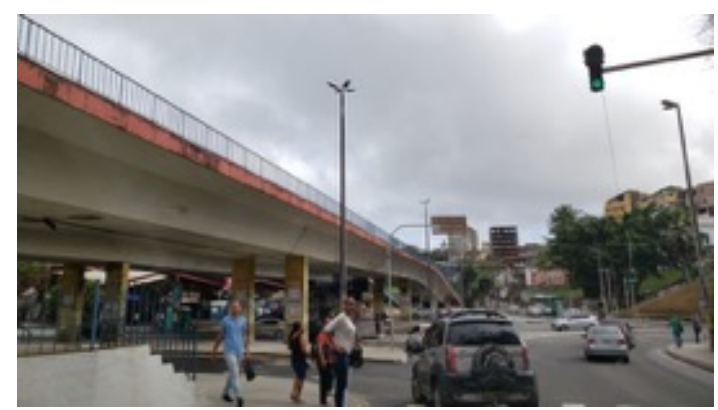

Figura 1 - Vista Geral

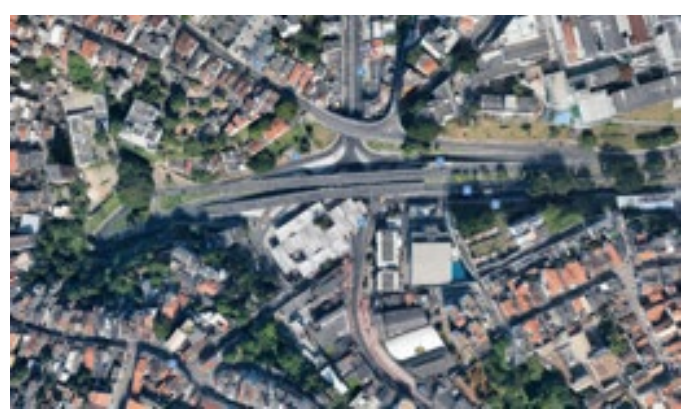

Figura 2 - Vista Aérea (Fonte: Google Earth)

A mesoestrutura é constituída por 10 pilares, numerados conforme detalhado, dispostos em 5 linhas com 2 elementos cada. A seção transversal dos pilares é retangular, nas dimensões de 1,25 $\mathrm{m} \times 0,60 \mathrm{~m}$, todos em concreto armado moldado "in loco". Os aparelhos de apoio são em neoprene.

A superestrutura em concreto armado é composta por 6 vãos, sendo a seção transversal do Viaduto em estrutura de caixão com lajes superior e inferior e almas externas, denominadas como sendo alma externa esquerda e alma externa direita, havendo ainda as lajes em balanço em ambos os lados, as quais foram denominadas como sendo esquerda e direita.

O pavimento verificado na OEA é asfáltico, com duas faixas de rolamento, um único sentido de tráfego. Não possui acostamento ou faixa de segurança, possuindo calçada. Não há barreira rígida, nem defensas metálicas nas proximidades da obra. Há guarda-corpo metálico, em ambos os lados da pista.

Verifica-se a presença de juntas de dilatação, próxima aos pilares 7 e 8 e extremidades, e o sistema de drenagem que atua por gravidade nos trechos inclinados, onde a água pluvial escoa pela sarjeta e é encaminhada aos bueiros, havendo pingadeiras na estrutura.

Conforme se verifica no Anexo G da NBR 9452 (ABNT, 2016), a convenção de nomenclatura da OAE é classificada como longarina em estrutura celular com almas interna e externa, com lajes em balanço, calçada, sem barreira fixa, com a presença de guarda corpo.

\section{RESULTADOS E DISCUSSÃO}




\subsection{Manifestações Patológicas Verificadas na OAE}

Conforme inspeção realizada no local, destacamos as seguintes manifestações patológicas conforme famílias de elementos:

\subsubsection{Aparelhos de apoio}

Os aparelhos de apoio (Figura 3), constituídos por suportes em neoprene, estes situados entre os pilares e a laje inferior, são responsáveis pela absorção dos esforços gerados pela movimentação da estrutura, e se encontram, de forma geral, deteriorados, deformados, apresentando redução de seção em alguns locais, principalmente nos pilares 7 e 8 .

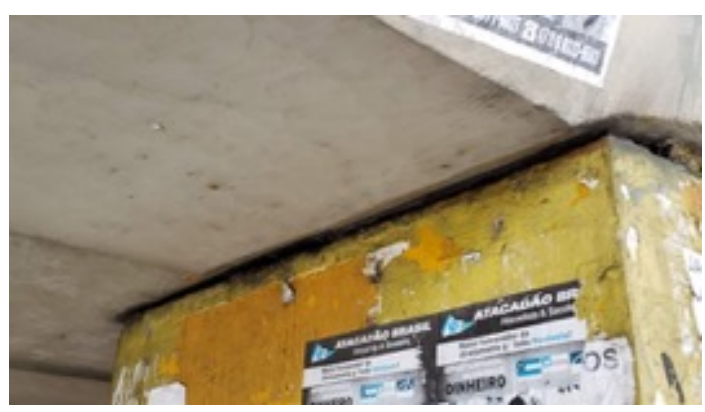

Figura 3 - Apoio em neoprene

\subsubsection{Pilares}

O Pilar 2 apresenta desplacamento de concreto na sua ligação com a Alma externa direita, conforme Figura 4.

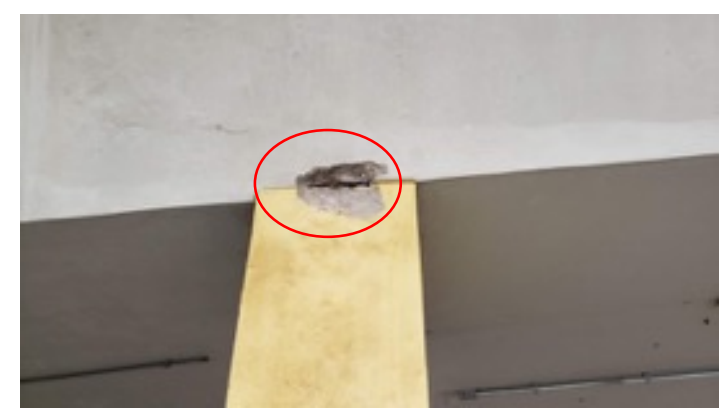

Figura 4 - Deplacamento Pilar 2

Os Pilares 3 e 4 apresentam grandes manchas de umidade (Figura 5), como também, apresentam crescimento de vegetação em toda a sua extensão, principalmente o pilar 4, o que gera danos à estrutura, seja pela ação mecânica das raízes, ou pelo acúmulo de umidade no local, conforme Figura 6. Ressalta-se a gravidade da vegetação verificada no local, visto que esta pode vir a movimentar o apoio e desestabilizar o tabuleiro por conta das tensões provocadas pelo desenvolvimento da planta. 


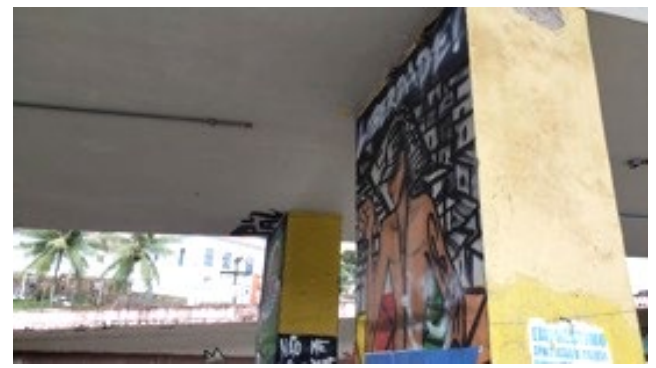

Figura 5 - Manchas Pilares

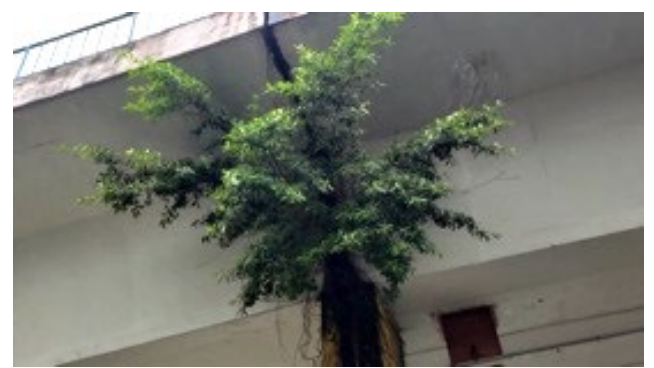

Figura 6 - Crescimento de vegetação no Pilar 4

O Pilar 3 apresenta, conforme Figura 07, em alguns locais, alto grau de degradação do concreto, que apresenta desplacamento da cobertura de proteção, com exposição das ferragens que se encontram oxidadas, apresentando também grande concentração de umidade, e indícios de carbonatação.

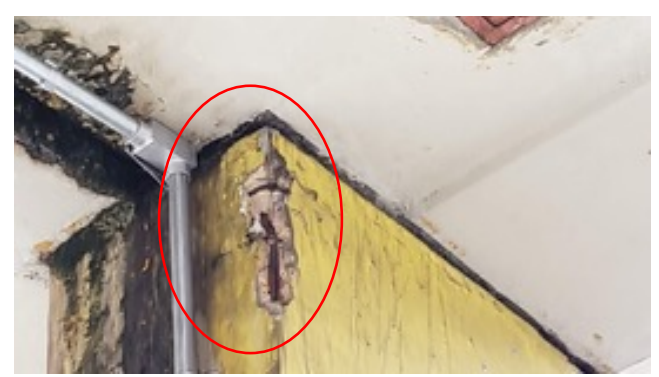

Figura 7 - Desplacamento de Concreto e exposição de ferragens no pilar 3

Os Pilares 5 e 6 apresentam manchas de umidade, conforme Figura 8, com desplacamento de concreto de recobrimento e armaduras expostas em suas bases.

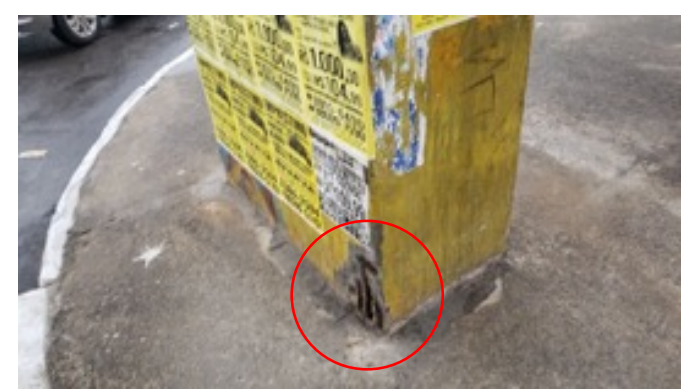

Figura 8 - Armadura exposta no Pilar 5

Observa-se na Figura 9, que os Pilares 7 e 8 apresentam manchas de umidade, e, verifica-se que o recobrimento do concreto em suas bases foi reparado. Porém, constata-se por inspeção visual que este recobrimento foi recomposto por argamassa com aparência porosa, aparentemente inapropriado para tal. Desta forma, há a necessidade de retirada do recobrimento executado, tratamento das ferragens, com possível recomposição da seção da armadura, e aplicação de novo recobrimento em argamassa estrutural de alta resistência. 


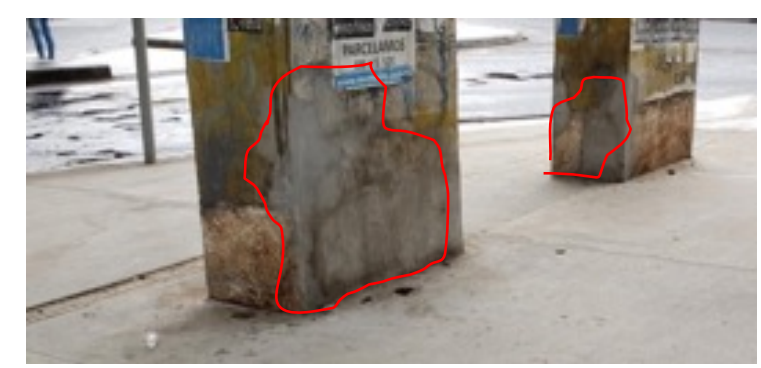

Figura 9 - Recomposição de recobrimento de armadura nos Pilares 7 e 8

\subsubsection{Cortina Cabeceira Sul}

A contenção em concreto armado situada na cabeceira sul da OAE (Figura 10), apresenta alto grau de deterioração, onde verifica-se exposição das armaduras, desplacamento e fissuração do concreto no local.

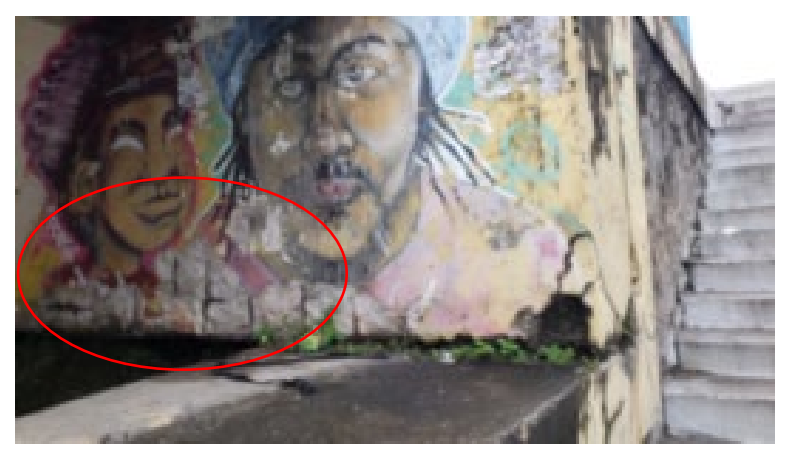

Figura 10 - Deterioração da estrutura de contenção na Cabeceira Sul da OAE

\subsubsection{Mesoestrutura}

Verifica-se por toda a superestrutura composta pela laje inferior, almas externas e lajes em balanço a presença de manchas de umidade causadas por sistema de drenagem deficiente, uma vez que, embora o escoamento da água seja por gravidade até os bueiros coletores, há acúmulo de água na sarjeta. Além da inclinação inadequada, o escoamento da água é prejudicado com o acúmulo de material (sujeira) na sarjeta. Observa-se que parte dessa água está infiltrando para o interior do caixão, pela grande quantidade de manchas de umidade e eflorescências verificadas, não havendo, aparentemente, sistema de drenagem no interior do caixão. O desenvolvimento de anomalias é facilitado com a presença de água, principalmente a ocorrência de corrosão das armaduras, além de promover a sua rápida evolução, contribuindo também para a deterioração do concreto.

Verifica-se no Vão 1, conforme Figura 11, situado entre a Cabeceira Norte e os Pilares 1 e 2, a presença manchas causadas fogueiras provenientes de habitações irregulares sob a OAE, de eflorescências, fissuras e exposição de armaduras na laje inferior, almas externas e lajes em balanço por toda a sua extensão. 


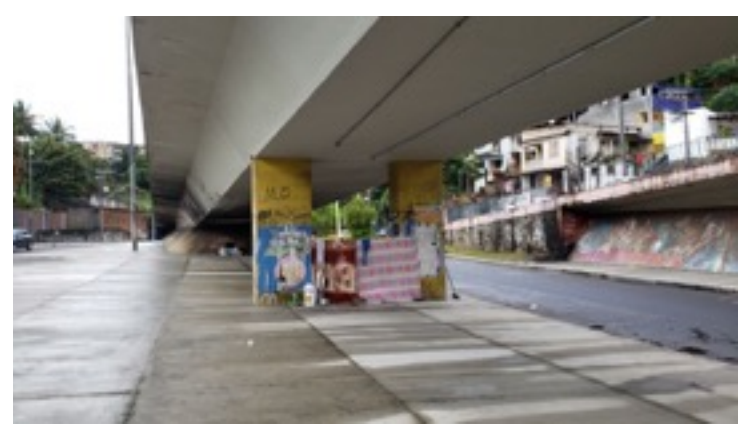

Figura 11 - Vista Vãos 1 e 2, Pilares 1 e 2

Conforme Figuras 12, 13, 14, 15, observa-se no vão 3 destaca-se a presença de fissuras na laje inferior, como também danos à estrutura (laje inferior e alma externa direita) com exposição e rompimento de armaduras, causados por provável impacto de veículo.

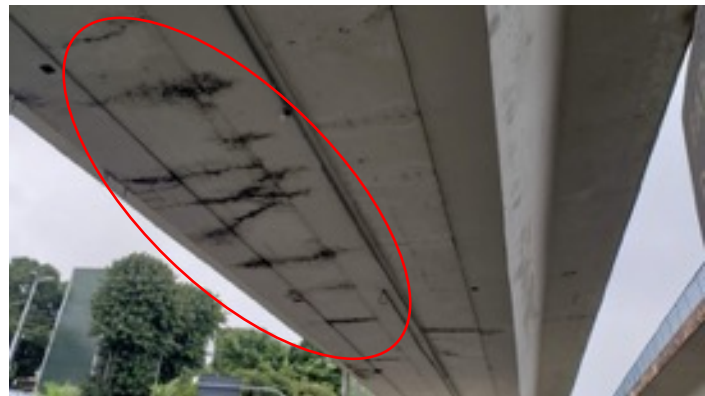

Figura 12 - Fissuras Vão 3

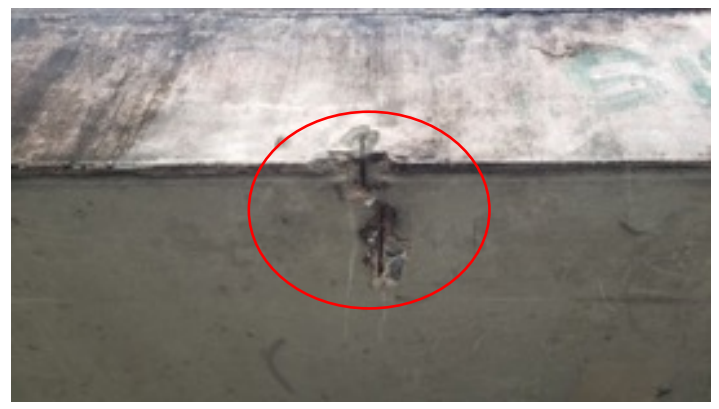

Figura 14 - Laje Balanço Direita

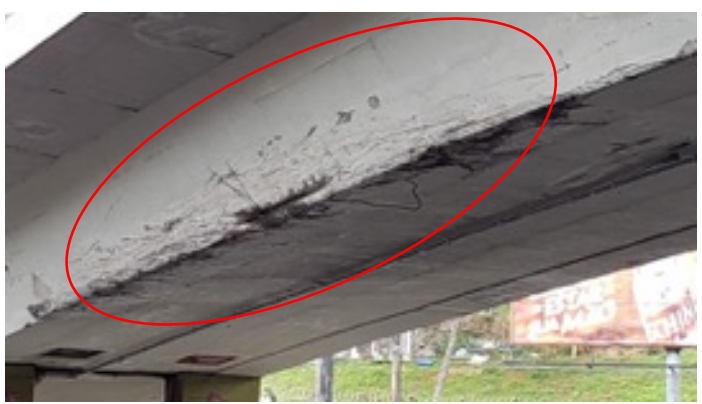

Figura 13 - Rompimento de armadura Vão 3

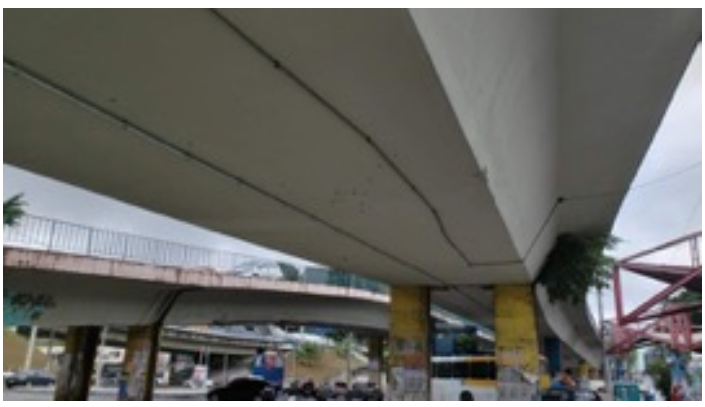

Figura 15 - Alma Externa Direita

\subsubsection{Pavimentação e Junta de Dilatação}

As juntas de dilatação encontram-se, de modo geral, obstruídas pela cobertura asfáltica, com surgimento de trincas e fissuras nessas áreas, estas, decorrentes da movimentação da estrutura, conforme Figuras 16 e 17. Na face superior da OAE verifica-se sobre o tabuleiro da laje superior a execução de pavimento do tipo flexível constituído por massa asfáltica CBUQ. Especificamente no pavimento flexível verificou-se de maneira generalizada, a ocorrência de áreas com reparos deficientes e desagregação, além de observadas diversas trincas e fissuras região com recalque do revestimento asfáltico. 


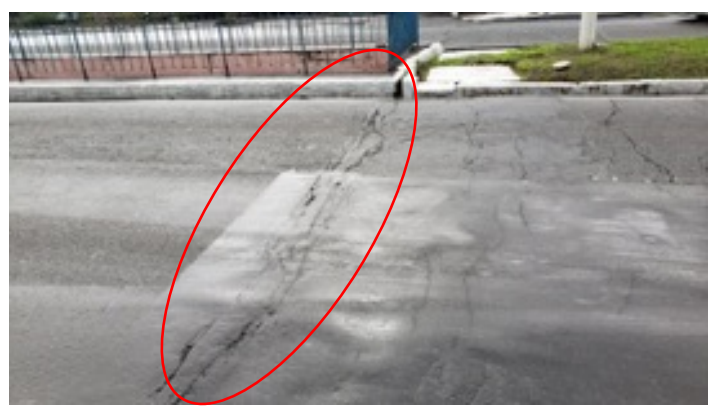

Figura 16 - Pavimento sobre junta de dilatação

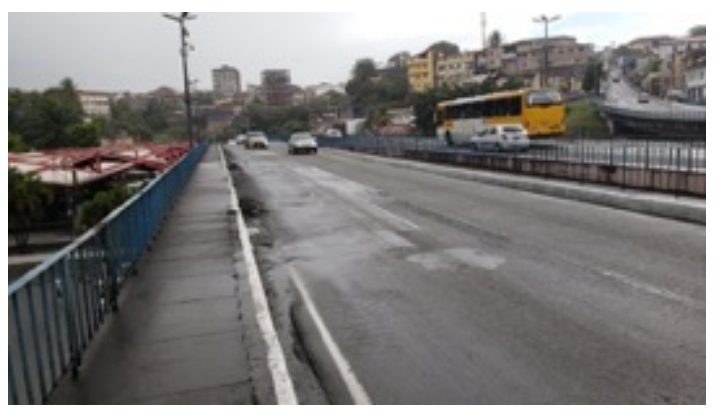

Figura 17 - Pavimentação

\subsubsection{Calçada e Guarda Corpo}

Verifica-se que as calçadas, assim como o guarda corpo lateral, apresentam danos diversos, com necessidade de reparos, conforme se observa na Figura 18.

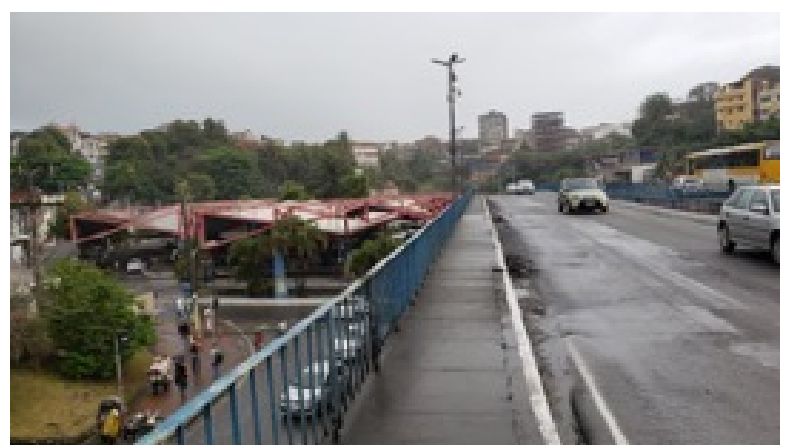

Figura 18 - Vista Calçada e Gradis

\subsection{Quantificação dos danos}

Considerando as manifestações patológicas verificadas na OAE constadas conforme inspeção visual realizada durante visita técnica, classificou-se, primeiramente, os elementos por famílias conforme suas funções estruturais, seguindo com as etapas referentes à metodologia adotada, sendo estas: mensuração, quantificação e definição do grau de deterioração.

Assim, após classificação de 9 famílias de elementos, calculou-se cada Grau de deterioração da família (GDF) referente a estas, aplicando-se em seguida os respectivos Fr definidos na Tabela 3, conforme demonstrado na Tabela 5.

Tabela 5 - Resultados dos respectivos Gdf e Fr por família de elemento

\begin{tabular}{|c|l|c|c|}
\hline Item & Elementos Avaliados & Gdf & Fr \\
\hline 1 & Pilares Principais & 225,71 & 5 \\
\hline 2 & Viga & 157,11 & 5 \\
\hline 3 & Lajes & 70,47 & 4 \\
\hline 4 & Aparelhos de Apoio & 137,84 & 4 \\
\hline 5 & Cortinas & 72,86 & 4 \\
\hline 6 & Juntas de Dilatação & 186,48 & 3 \\
\hline 7 & Pista de Rolamento & 87,27 & 1 \\
\hline
\end{tabular}




\begin{tabular}{|l|l|l|l|}
\hline 8 & Calçadas & 87,27 & 1 \\
\hline 9 & Guarda Corpo & 80,00 & 1 \\
\hline
\end{tabular}

Em seguida foi possível calcular conforme a equação 5, o grau de deterioração da estrutura - Gd, cujo resultado é de 134,48, caracterizando-se a estrutura analisada, conforme Tabela 4, com um nível de deterioração crítico. Portanto, conclui-se que a OAE apresenta a necessidade de inspeção especial emergencial, de acordo a NBR 9452 (ABNT, 2016), com prazo de intervenção imediata.

\section{CONCLUSÃO}

O presente trabalho consistiu em um estudo de caso, cujo objetivo foi mensurar de forma numérica as condições da $\mathrm{OAE}$ em análise, conforme inspeção visual, classificando o estado atual da sua estrutura e indicando um prazo para adoção de intervenções para sua recuperação, através da metodologia GDE/UnB, adaptada por Verly (2015) para verificação de obras de arte especiais.

Após a aplicação da metodologia adotada, constatou-se que o Viaduto Marta Vasconcelos, situado no bairro do Aquidabã, município de Salvador, encontra-se em situação caracterizada como crítica, devendo este ser submetido a inspeção especial, com adoção de plano de intervenção imediata para sua recuperação. Verifica-se que a família dos pilares é a que apresenta maior grau de deterioração.

Conclui-se também que a metodologia GDE/UnB se mostrou apropriada ao estudo desta estrutura, estando o resultado encontrado coerente com a expectativa gerada após a sua vistoria, onde constatou-se diversas manifestações patológicas descritas anteriormente, das quais destacam-se: ausência de recobrimento, oxidação das armaduras, desplacamento de concreto e ausência de tratamento nas juntas de dilatação.

É relevante destacar que se observa no município de Salvador, diversas Obras de Arte Especiais se encontram em situação semelhante à analisada, sendo fundamental e emergencial a adoção de inspeções e execução de plano de intervenções nestas estruturas, por parte do poder público.

\section{REFERÊNCIAS}

Associação Brasileira de Normas Técnicas (2014). NBR 6118: Projeto de estruturas de concreto - Procedimento. Rio de Janeiro

Associação Brasileira de Normas Técnicas (2016). NBR 9452: Inspeção de pontes, viadutos e passarelas de concreto. Rio de Janeiro

Associação Brasileira de Normas Técnicas (2013). NBR 15575: Edificações Habitacionais Desempenho - Parte 1. Rio de Janeiro

Bertolini, L. (2010), “Materiais de construção: patologia, reabilitação, prevenção”. São Paulo: Oficina de Textos.

Castro, E.K. (1994), "Desenvolvimento de Metodologia para Manutenção de Estruturas de Concreto Armado". Dissertação de Mestrado, Departamento de Engenharia Civil, Universidade de Brasília, Brasília, DF. 
Costa, H. O. (2016). "Avaliação de patologias em obras de arte especiais utilizando a metodologia GDE/UnB”.

De Lima, H. J. N., et al. (2019). "Manifestações patológicas em viadutos de concreto estrutural: estudo de caso em Brasília/DF”. Revista InterScientia.

Euqueres, P., et al. (2011). "Metodologia de inspeção em estruturas de pontes de concreto armado".

Fernández Cánovas, M. (1988). "Patologia e terapia do concreto armado. Tradução de M. Celeste Marcondes, Carlos Wagner Fernandes dos Santos, Beatriz Cannabrava.". São Paulo: Pini.

Ferreira, B. M. (2016). “Análise quantitativa da Ponte do Bragueto-DF utilizando a metodologia GDE/UnB. ,

Fonseca, R. P. (2007). "A estrutura do Instituto Central de Ciências: Aspectos históricos, científicos e tecnológicos de projeto, execução, intervenções e propostas de manutenção." Dissertação de Mestrado em Estruturas e Construção Civil, Departamento de Engenharia Civil e Ambiental, Universidade de Brasília, Brasília, DF.

Medeiros, A. G. de (2015). "Análise de durabilidade da ponte do Rio do Carmo utilizando ensaios não destrutivos, norma DNIT e a metodologia GDE/UNB."

Mendes, V. G. (2014). "Avaliação quantitativa dos danos na estrutura de concreto armado da Biblioteca Central da UnB e proposta de plano de gestão da manutenção dos edifícios da Universidade."

Moreira, R. D. (2015). "Levantamento das manifestações patológicas em uma instituição de ensino superior no Distrito Federal: estudo de caso".

Teles, R. F. (2018). “Análise quantitativa de estruturas similares em concreto armado utilizando a metodologia GDE/UNB-estudo de caso."

Verly, R. C. (2015). "Avaliação de metodologias de inspeção como instrumento de priorização de intervenções em obras de arte especiais". 